\section{P070 DETERMINATION OF ANTIBIOTIC SUSCEPTIBILITY AND EFFICACY BY VITA-PCR}

${ }^{1}$ Nicole Lima*, ${ }^{2}$ Claire Gibbs, ${ }^{3}$ Wilhelmina Huston, ${ }^{2}$ Alison Todd. ${ }^{1}$ University of New South Wales, School of Biotechnology and Biomolecular Sciences, SYDNEY, Australia; ${ }^{2}$ SpeeDx Pty Ltd, Eveleigh, Australia; ${ }^{3}$ University of Technology Sydney, School of Life Sciences, Ultimo, Australia

\subsection{6/sextrans-2019-sti.269}

Background Major challenges in the management of infectious diseases include treatment failure due to antimicrobial resistance (AMR) and the lack of a reliable test of cure (TOC). Whilst culture is a trusted method it is slow, and with the widespread use of nucleic acid amplification tests (NAATs), many labs no longer retain culture capabilities. NAATs can assess AMR by detecting microbial mutations associated with resistance; however, this approach requires knowledge of the molecular mechanism(s), and as new mutations emerge, tests need to be reconfigured. Uses of NAATs for TOC is problematic since residual DNA and RNA have been reported following effective therapy. The VITA method provides a new tool which can overcome current drawbacks.

Methods The VITA Index is the ratio of the number of copies of a gene and its associated transcripts to those of a non-transcribed region of DNA. It provides a relative measure of active transcription regardless of the quality/quantity of specimen. The approach has several applications. Firstly, following addition of antibiotic to a specimen, e.g. for $5 \mathrm{~min} / 37^{\circ} \mathrm{C}$ or $15 \mathrm{~min} / \mathrm{room}$ temperature, Total Nucleic Acid can be amplified by VITA RT-PCR. Comparison of the VITA indices \pm drug will relate to antibiotic resistance or sensitivity. VITA RT-PCR can later provide a TOC, where VITA indices of a specimen can fall either above or below a predetermined threshold, indicating a viable or cleared infection respectively.

Results Both sensitivity and resistance to different antibiotics has been demonstrated in vitro on Chlamydia trachomatis, with significant decreases in VITA in the presence of drug in sensitive $(p<0.05)$, but not in resistant strains. Further, urine obtained from a patient post-treatment was analysed, and consistent with clinical evidence of ongoing infection, the VITA Index indicated viable chlamydia.

Conclusion In conclusion, VITA provides a powerful new approach for rapid determination of AMR and TOC.

Disclosure No significant relationships.

\section{P071 POLICE HARASSMENT AND HIVISTI RISK BEHAVIORS AMONG A SAMPLE OF PEOPLE WHO INJECT DRUGS ON THE U.S.-MEXICO BORDER}

${ }^{1}$ Oscar Beltran*, ${ }^{2}$ Julia Lechuga, ${ }^{3}$ Gilberto Perez, ${ }^{4}$ Rebeca Ramos, ${ }^{1}$ Maria Ramos Rodriguez. ${ }^{1}$ Programa Compañeros, A.C., Juarez, Mexico; 'Lehigh University, Bethlehem, USA; ${ }^{3}$ Programa Compañeros, Cd Juárez, Mexico; ${ }^{4}$ Alliance for Border Collaboratives, El Paso, USA

\subsection{6/sextrans-2019-sti.270}

Background The number of people who inject drugs on the U.S.-Mexico border has been increasing over the last years and has become a public health concern due to their vulnerability to HIV and other sexually transmitted infections (STIs). We explored the HIV/STI risk behaviors of people who inject drugs (PID) and their relationship to police harassment.
Methods The sample for this study included 200 PID $(75 \%$ male, 25\% female) recruited through respondent driven sampling methodology. Data analysis was conducted using SPSS v.25; independent sample t-test was used to identify mean differences across PID experiencing police harassment during the past three months vs. PID who did not experience police harassment in the last three months; chi-squared analysis was used to explore proportional differences on substance use and HIV/STIs sexual risk behaviors.

Results Overall, 1.9\% of participants reported being diagnosed with HIV, and $23.3 \%$ with hepatitis C. PID who experienced police harassment reported higher use of other drugs: marijuana $(\mathrm{OR}=1.78, \quad 95 \% \mathrm{CI}=[1.05,3.04], \mathrm{p}=0.015)$, inhalants $(\mathrm{OR}=2.06,95 \% \mathrm{CI}=[1.40,3.03], \mathrm{p}<0.001)$, cocaine $(\mathrm{OR}=1.78$, $95 \% \mathrm{CI}=[1.14,2.80], \mathrm{p}<0.01), \quad$ crystal $\quad(\mathrm{OR}=2.11, \quad 95 \% \mathrm{CI}=$ $[1.27,3.52], \mathrm{p}<0.01)$, methamphetamines $(\mathrm{OR}=2.06,95 \% \mathrm{CI}=$ $[1.22,3.48], \mathrm{p}<0.01), \quad$ tranquilizers $\quad(\mathrm{OR}=2.02, \quad 95 \% \mathrm{CI}=$ [1.35,3.02], $\mathrm{p}<0.001)$. Regarding risk behaviors, PID who experience police harassment reported higher numbers of sex partners (Mean: 10.99 vs. 5.72, $\mathrm{p}=0.024$ ) and condom-less sex (Mean: 3.18 vs. 1.55, $\mathrm{p}=0.042$ ). Men reported higher rates of sex with other men $(\mathrm{OR}=1.66,95 \% \mathrm{CI}=[1.25,2.19]$, $\mathrm{p}<0.01)$. More PID reported being gang raped $(\mathrm{OR}=2.15$, $95 \% \mathrm{CI}=[1.73,2.68], \mathrm{p}<0.001)$ and having condom-less sex with a person known to have HIV $(\mathrm{OR}=1.48,95 \% \mathrm{CI}=$ $[1.10,1.99], \mathrm{p}<0.01)$.

Conclusion There is a clear relationship between experiencing police harassment, engaging in HIV high-risk behaviors, and higher consumption of other drugs among PID. Understanding the structural dynamics of discrimination and stigma among this group (e.g. double stigma, being MSM) could lead to a deeper understanding of these relationships.

Disclosure No significant relationships.

\section{P073 FROM SILOS TO BUCKETS: A QUALITATIVE STUDY OF HOW SEXUAL HEALTH CLINICS CAN ADDRESS MENTAL HEALTH \& SUBSTANCE USE NEEDS}

${ }^{1}$ Travis Salway*, ${ }^{2}$ Stéphanie Black, ${ }^{3}$ Naomi Dove, ${ }^{1}$ Jean Shoveller, ${ }^{3}$ Dean Mirau, ${ }^{3}$ Troy Grennan, ${ }^{4}$ Mark Gilbert. 'University of British Columbia, School of Population and Public Health, Vancouver, Canada; ${ }^{2}$ University of British Columbia, Vancouver, Canada; ${ }^{3} B C$ Centre for Disease Control, Vancouver, Canada; ${ }^{4} B C$ Centre for Disease Control, Clinical Prevention Services, Vancouver, Canada

10.1136/sextrans-2019-sti.271

Background In 2016-17, we surveyed clients of six sexual health clinics in Greater Vancouver. Consistent with studies from the US and Europe, we measured high rates of mental health and substance use (MHSU)-related service needs (39\%). As a next step, we interviewed sexual health providers to characterize barriers and opportunities to addressing clients' MHSU needs.

Methods We conducted in-depth interviews with 22 providers (14 nurses, 3 physicians, 3 administrators, 2 other health professionals) from six sexual health clinics in British Columbia.

Results Providers consistently affirmed that MHSU-related concerns (including both 'chronic' conditions related to mood or anxiety and episodic crises) co-occur with sexual health concerns among clients presenting to sexual health clinics. In particular, anxiety was frequently cited-sometimes in association with a client profile that constituted low risk for sexually 